\title{
The Factors Contributing to Teacher Predictions of Spelling Ability, and the Accuracy of Their Assessments
}

\author{
KENDALL KOLNE \\ McGill University; Centre for Research in Brain, Language and Music \\ LAURA M. GONNERMAN \\ McGill University; Centre for Research in Brain, Language and Music \\ ALEXANDRA MARQUIS \\ United Arab Emirates University \\ PHAEDRA ROYLE \\ University of Montréal; Centre for Research in Brain, Language and Music \\ SUSAN RVACHEW \\ McGill University; Centre for Research in Brain, Language and Music
}

\section{Abstract}

In this study, teachers of kindergarten and grade one French-speaking students indicated the likelihood their students would develop later spelling difficulties. Results showed that language measures, language background, the education levels of parents, and home literacy practices predicted whether children would be identified as at-risk. Moreover, children's oral language skills accounted for even more of the variance in teacher ratings than other variables. Spelling performance assessed 1-year later from a subset of children indicated that the teacher predictions were accurate. Thus, teachers appear to be an effective source for predicting children's future literacy performance.

The early identification of children at-risk for the development of reading or spelling problems is essential to ensure that these children receive preventative interventions during a critical period. In the absence of early identification and intervention, the effects of reading difficulty may be unalterable beyond grade one (Harm, McCandliss, \& Seidenberg, 2003). However, if provided with early intervention, it is possible for reading outcomes to be improved (e.g., Catts, 1991; Connor, Alberto, Compton, \& O'Connor, 2014; Leppänen, Niemi, Aunola, \& Nurmi, 2004; Torgesen, 2002). Therefore, identifying children who will potentially experience delays in the acquisition of literacy is critical.

Teacher ratings have been proposed as both an efficient and cost-effective method of achieving such assessment (Glover \& Albers, 2007; Kettler \& Albers, 2013). Formal reading instruction occupies more time than any other activity in the first, second and third grades (Perfetti \& Curtis, 1986) and reading success is of the highest priority within the Canadian education system (Council of Ministers of Education, Canada [CMEC], 
2009), so it is plausible that teachers have an accurate perception of progress of their students' literacy development. In fact, according to Wolf (1997), teacher-rating scales are the second most frequently used measure in education (teacher-made tests being the most frequently used). Additionally, whereas formal assessment measures may be expensive and limited in scope (as they only measure children's performance at one time), teacher assessments are inexpensive and take into account children's performance across time (Beswick, Willms, \& Sloat, 2005). Thus, teacher assessments may be a valuable tool in providing early measurement of risk status.

For teacher ratings to be used effectively as a gauge of children's risk for developing literacy difficulty, it is essential to evaluate the basis for these assessments, and understand the factors that teachers consider when making their assessments. Researchers generally concur that teacher ratings are moderately accurate at predicting students' later reading skills (Beswick et al., 2005; Feinberg \& Shapiro, 2009; Gijsel, Bosman, \& Verhoeven, 2006; Südkamp, Kaiser, \& Möller, 2012; Teisl, Mazzocco, \& Myers, 2001), however the factors that contribute to these assessments have yet to be delineated. In a typical classroom environment, teachers have access to a range of information about their students. This information includes not only their academic competence, but also their social, emotional, and behavioural characteristics and any or all of these factors may potentially influence the assessments teachers make of their students' performance and future risk of academic difficulties.

Research robustly indicates that phonological awareness is the strongest predictor of literacy skills, including later reading and spelling abilities (e.g., Adams, 1990; Bradley \& Bryant, 1991; Ouellette \& Senechal, 2008; Wagner \& Torgesen, 1987). Speech perception is closely related to phonological awareness (Rvachew \& Grawburg, 2006), and children with poor reading and spelling skills often have difficulties with speech perception (Joanisse, Manis, Keating, \& Seidenberg, 2000; Overby \& Bernthal, 2008; Pennala et al., 2010). Additionally, there is evidence that morphological awareness makes a significant and independent contribution to the prediction of later achievements in the literacy domain (Deacon \& Kirby, 2004; Nagy, Berninger, \& Abbott, 2006). In particular, there are reciprocal relationships between morphological knowledge and the acquisition of spelling starting as early as grade one (Levin, Ravid, \& Rapaport, 2001; Pacton \& Deacon, 2008). Moreover, other aspects of oral language functioning, including speech errors (Nathan, Stackhouse, Goulandris, \& Snowling, 2004) and immature grammar (Catts, Fey, Zhang, \& Tomblin, 2001) are also risk factors for delayed acquisition of literacy. Children with speech sound disorders are at particular risk for difficulties in spelling acquisition; when speech deficits are combined with language impairment, both spelling and reading are impacted (Bird, Bishop, \& Freeman, 1995; Lewis, Freebairn, \& Taylor, 2000; Lewis, O'Donnell, Freebairn, \& Taylor, 1998). To summarize, the scientific literature has established that delays in oral language and emergent literacy skills provide a reliable indication of elevated risk for reading and writing impairments; therefore, it is important that teachers are sensitive to students' abilities in these domains, and that they take this information into account when assessing their students' risk for literacy difficulty. However, the degree to which teachers can assess performance in some of these domains within a classroom environment without formal, standardized testing, is not clear.

In addition to observing their students' skills in the literacy domain, teachers may 
have access to various kinds of information about their students' home backgrounds and classroom behaviours that may contribute to their assessments. For example, Beswick et al. (2005) report a gender bias, as the teachers tended to rate the reading skills of females more positively than males. This finding is consistent with other evidence suggesting that more boys tend to be diagnosed with learning and behavioural difficulties than girls (e.g., Bruchmüller, Margraf, \& Schneider, 2012; Shaywitz \& Shaywitz, 2003; Tomblin, Zhang, Buckwalter, \& Catts, 2000). In addition to gender, teachers in the Beswick study were more negative in their ratings of children repeating kindergarten, children with mothers who had low education levels and children with behavioural difficulties in the classroom. Several other factors from the home environment have been shown to influence literacy development, including single- vs. two-parent homes (Hampden-Thompson, 2013), the language background of the child (Bialystock, McBride-Chang, \& Luk, 2005), the child's enjoyment of reading (Chiu \& McBride-Chang, 2006), motivation to read (McGeown, Duncan, Griffiths, \& Stothard, 2014) and engaging in literacy activities with siblings (Baker, Scher, \& Mackler, 1997; Sokal \& Piotrowski, 2011). Thus, there is an array of factors from the home environment influencing children's literacy development, any of which may contribute to teachers' ratings, depending on the knowledge available to them.

Predicting risk of literacy difficulties may be particularly challenging for teachers working in a low-income environment, given that poverty itself is a risk factor for slower acquisition of literacy (Buckingham, Bearman, \& Wheldall, 2014; Hecht, Burgess, Torgesen, Wagner, \& Rashotte, 2000). However, Hecht and Greenfield (2001) provide evidence that teachers remain accurate in a low socioeconomic status (SES) context. They tested a group of grade one students exposed to poverty, with the aim of identifying predictors of reading growth in this population. In the spring of the children's first-grade year, teachers were asked to rate each of their students' academic abilities compared to their classmates. In addition, the children were administered a battery of reading-related tests which included print and vocabulary knowledge and phonological awareness. The results revealed that teacher ratings predicted as much variance in third grade word reading as the measures of print and vocabulary knowledge and phonological awareness. Moreover, identification of children who proved to be poor readers in third grade was equivalent when teacher ratings or grade one reading was used as the predictor. Thus, it seems that despite the higher risk of reading difficulty in a low SES population, teachers remain effective at predicting their students' future literacy skills.

Given the range of information available to teachers, it is important to determine what information guides their assessments of their students' literacy abilities, and in what way. This paper reports the results of two experiments that add to the current literature by focusing on spelling rather than reading as the outcome and by examining these issues in a francophone environment. The goal of the first experiment in our study was to examine correlates of teacher risk ratings for future difficulties. After asking kindergarten teachers to rate the degree to which they felt each of their students was at risk for developing spelling difficulties, we compared the relative contribution of a range of factors, including oral language measures, parental education, family background, and case history information, to the teachers' predictions. In this way, we are able to examine which factors had the strongest relationship with teacher ratings, and which were generally not related to the teachers' predictions.

For teacher ratings to be used effectively, it is important to examine the extent to 
which teachers are able to assess the literacy skills of their students with accuracy and validity. As previously mentioned, there is a consensus in the literature that teachers' judgments have a moderately strong correlation with academic achievement (see Südkamp et al., 2012 for review). The goal of our second experiment was to replicate the findings for accuracy in teacher ratings as reported in previous research. To do this, we measured the spelling performance of a subset of the children in our study at the end of grade one, and compared the relative contributions of the teacher predictions, as well as measures of maternal education and oral language ability in kindergarten to their spelling performance. Thus, we are able to both determine the accuracy of the teacher's ratings, and compare it to other well-established predictors of literacy achievement.

The children described in this report were recruited to take part in a larger study whose goal was to develop a tablet-based screening test to identify children entering school who are most at risk for experiencing difficulty with spelling and other literacy skills in the second grade. The children received assessments of their oral language abilities and their teachers provided an opinion about their future risk for literacy problems as they progressed through school. These data were used to develop a screening test for identifying children who may be at risk for poor spelling skills in later grades. The teachers' predictions themselves are the focus of this report, along with some preliminary data regarding the children's early spelling abilities in grade one.

\section{Experiment 1}

\section{Method}

Participants. The participants were 114 children attending French-language schools in a suburb of Montréal, Québec, that is an area of high immigration with $61 \%$ of the total population speaking French as the 'mother-tongue' and 28\% speaking neither English nor French as the mother-tongue (Statistics Canada, 2011). Fifty-nine percent of the parents in this study were monolingual French speakers, and $41 \%$ were either bilingual speakers, or monolingual speakers of language other than French. As a result, the native languages of the children were diverse and included English, Arabic, Spanish, Haitian Creole, Italian, Greek, Lao, Polish, Romanian, Asu, and Khmer. By law, immigrant children must be educated in French in the province, and the language of instruction was one hundred percent French in the schools attended by the children recruited to this study (i.e., there was no formal English instruction).

The Ministry of Education in the Province of Quebec (Ministère de l'Éducation, du Loisir et du Sport, MELS, 2013) has created a detailed language arts curriculum, to which preschool and elementary school teachers are required to adhere ${ }^{1}$. This curriculum is grouped around 4 skills: writing a variety of texts, reading a variety of texts, appreciating literary works, and oral communication. Writing instruction specifically focuses on six sections: lexicon, spelling, conjugation, agreement, syntax and punctuation, and organization and coherence of text. Within each of these sections, the curriculum prescribes what students are expected to learn each year, based on "recent

\footnotetext{
${ }^{1}$ The details of the exact French language curriculum can be found in the Quebec Program of Study, on the MELS website: http://www1.mels.gouv.qc.ca/progressionPrimaire/francaisEns/index.asp
} 
research in the fields of teaching French, applied linguistics and learning, and the principles of the current grammar" (MELS, 2013). Within the spelling section, ways to gain knowledge are carefully laid out in the curriculum. For children in grade one, this instruction includes associating graphemes and phonemes, identifying orthographic details of words, copying words and checking their spelling, and using mnemonics for irregular spellings.

The study and associated testing protocols were approved by the internal review boards from both McGill University and Université de Montréal Faculties of Medicine. The children were recruited from the schools by sending letters home and asking parents or guardians to return a signed consent for their child if they agreed to their child's participation. The consent letter briefly described the purpose of the study (to examine the link between oral language development and the acquisition of writing skills) in lay terms. Each and every procedure to be employed was described in detail including all parent questionnaires and tests to be administered to their children. Issues regarding risks, benefits, privacy, rights and responsibilities of participants and researchers were discussed, and contact information for researchers and the institutional review board was provided. Information was also provided to groups of parents verbally at parent-teacher night and, after receiving signed consent forms, individually over the phone. Child assent to participation was obtained during each assessment session.

The children were recruited and assessed either at the very end of the kindergarten year (maternelle) or the beginning of grade one (première année). The sample comprises 43 children drawn from kindergarten classrooms with a mean age of 73.09 months $(S D=$ 3.72 ) and 71 children drawn from grade one classrooms with a mean age of 81.70 months $(S D=4.70)$. This sample is composed of all children attending the two schools who participated in the project (i.e., for whom consent was obtained and who were present in school on the days that research staff were in the school for testing). Children were not excluded for any reason (e.g., language background, developmental concerns or disabilities) other than missing data due to absence at school or lack of consent for participation from parent or child. Therefore, the sample included one confirmed case of hearing impairment, one confirmed case of autism, one confirmed case of Down Syndrome and one child with a congenital heart malformation. Across the two schools, 114 children were recruited but sufficient data was obtained for only 111 of those children. We did not receive teacher ratings for 1 child, and two children were absent on the day of testing, so these 3 children were excluded from all analyses. Two children did not complete the verb morphology task, and the children were only excluded from the relevant analyses for which their data was missing. Finally, we received parent reports from 109 parents in this study, and the 5 children for whom no reports were obtained were excluded from the relevant analyses.

All of the kindergarten and grade one teachers from the classrooms we tested provided ratings for our study. In total, 9 teachers were surveyed; 3 kindergarten, and 3 grade one teachers from one school, and 3 grade one teachers from the second school were included. In order to obtain a teaching license for teaching preschool or primary school in the province of Quebec, teachers must hold an undergraduate degree in preschool and elementary school education. Additionally, teachers are required to pass an 
English or French test set by the Minister of Education, depending on the primary language of instruction for a given school (Gouvernement du Québec, MELS, $2012^{2}$ ). Thus, all of the teachers included in this study had passed this test of French competency, and have an appropriate facility to teach in French, according to the Government of Quebec.

Procedure. The procedures involved three phases: (1) parents participated in a 15minute phone interview covering three questionnaires (literacy, child case history and family language background); (2) the child participated in an assessment of four aspects of his or her oral language skills (speech perception, phonological awareness, speech articulation accuracy, and morphological awareness); and (3) the child's teacher provided an opinion about the child's risk for experiencing future difficulties in the acquisition of written language skills.

With respect to the parental questionnaires, the home literacy questionnaire was modeled on an English questionnaire developed by Senechal, LeFevre, Thomas, and Daley (1998), and asked parents to rate the frequency with which they practiced a range of literacy-related activities at home, using a five point scale ranging from never to very frequently. The questions (after translation to French) inquired about shared reading activities (e.g., "At bedtime, how often do you or other family members read to your child?"), opportunities for emergent literacy development (e.g., "In a typical week, how often do you play rhyming games with your child?"), and explicit teaching of reading and writing skills (e.g., "In a typical week, how often do you teach your child to write his/her name?"). Three summary measures were derived from this questionnaire: frequency of shared reading activities; frequency of emergent literacy activities; frequency of reading and writing activities. The case history questionnaire (Appendix A) asked parents to provide information related to the child's birth, health and developmental history including family history of developmental problems and the use of any extra supports (e.g., speech therapy). Parental occupation and education was also probed. Four summary measures were derived from this questionnaire: a simple sum of the number of developmental concerns checked by the parent, including history of previous therapies: the highest possible score was eleven; a simple sum of the number of family history items checked by the parent with the highest possible score being four (mother, father, siblings, other family members); and the highest number of years of formal education achieved by each parent. Finally, an extensive language questionnaire (Appendix B) was administered if the child was exposed to any language other than French, revealing the total percentage of time that the child was exposed to French versus other languages in a variety of contexts (home, daycare, school, etc.), both with respect to other conversants in those environments and the presence of media such as radio and television.

Regarding language assessment, four tasks were administered in French in two half-hour test sessions for the children attending kindergarten, each language assessment

\footnotetext{
2 The details of the language competency requirements for obtaining a teaching license in Quebec can be found on the MELS website:

http://www.mels.gouv.qc.ca/fileadmin/site_web/documents/reseau/formation_titularisation/PermisEnseigne rHorsQuebec_Juillet2012_a.pdf
} 
lasting approximately 10 to 20 minutes. The tests were divided into two separate pairings: phonological awareness was paired with speech perception, and morphological awareness with speech production. Test order was counter-balanced within and across sessions, and the sessions occurred within two weeks of each other. For the children attending grade one, a shorter version of each test was administered in one session lasting approximately 20 minutes. The order of the tests was: phonological awareness, speech perception, speech production, and morphological awareness.

Phonological awareness was measured using the Test de Conscience Phonologique Préscolaire, an adaptation of the Phonological Awareness Test designed by Bird et al. (1995) for Quebec French by Brosseau-Lapré and Rvachew (2008, unpublished). This French adaptation involves computer administration of audio and visual stimuli. The full test, administered to the kindergarten children, is made of two parts of the TCP assessing onset and rime awareness. First, the child is presented with a picture of an animal; the child is then told the animal's name and further told that the animal likes things that sound like its name. The child is then presented with four words and corresponding pictures, and asked to select which of the four items the animal will like; the correct response being the word that rhymes with the animal's name (e.g., Lou $[\mathrm{lu}]$ - chou $[\mathrm{Ju}]$ 'cabbage'). The second part of this test measures onset awareness and segmentation. For this part, the child is told that the animal likes things that start with the same sound as its name (e.g., Sam [sam] - sol [sol] 'ground'). Each subtest begins with a number of practice trials during which feedback is provided to ensure that the child understands the procedure. Feedback is not provided for test trials. The instructions, animal name or sound stimulus, and response alternatives are provided to the child on every trial in order to reduce the memory load associated with the test. The test score is the number of correct responses out of 24 total items. The short version administered to the children in grade one included only the first part assessing rime awareness with 14 items.

Speech articulation accuracy was measured using the Test de Dépistage Francophone de Phonologie (TDFP; as described in Rvachew et al., 2013). This test is intended to assess the accuracy of consonant and vowel production. The full test administered to the kindergarten children consists of 30 target words that are representative of the characteristics of Quebec French according to phonemes, syllable shape, number of syllables and word length. The TDFP is a basic picture-naming task, where items are presented to children in full-colour. The slides depict two-to-four items per slide and are organized thematically. For example, one slide consists of a child playing with toy vehicles, including a truck, a helicopter, an airplane, and a train. The experimenter provides prompts to the child, to elicit the corresponding words. The prompts start by eliciting a spontaneous production and, if the child doesn't know the word, they progress to delayed imitation, and finally a direct imitation if needed. Responses were recorded using a Zoom1 stereo digital recorder at a sampling frequency of $44 \mathrm{kHz}$ and a quantization rate of 24 bits. The responses were transcribed by a Frenchspeaking graduate student with training in clinical phonetics and phonology. Consonants were scored as correctly or incorrectly articulated and the final score for each child was percent consonants correct across all 30 test items. The short version administered to the grade one children included only 10 items.

Speech perception was assessed using the Speech Assessment and Interactive 
Learning System (SAILS; Rvachew, 1994). It is a computerized two-alternative forcedchoice word identification task, and a version adapted for Quebec French was administered for this study. Children heard speech recorded from adults, typically developing children and children with phonological disorders. Children were required to identify whether or not each word presented is a good exemplar of the visually-presented target. In the full version administered to the kindergarten children, three target words were tested, e.g., gris [gвi] 'grey' associated with a grey square as the correct response alternative. The computer screen also presented a large $\mathrm{X}$ as the response alternative for words that did not sound like the word gris and a cartoon that filled in progressively as the child completed trials. Each block contained five correctly articulated words as well as five incorrectly articulated words which corresponded to typical misarticulations from younger children and children with Speech Sound Disorders. The task began with a block of ten practice trials ([gri] vs. [ni]) during which feedback was provided with reinstruction as required. Practice items were administered with feedback, and once the child displayed that they understood the task, the test blocks were administered. For the kindergarten children, a total of 6 blocks and 60 words were tested, while 2 blocks and a total of 20 test trials were presented to the children in grade one. The final score for each child, provided by the computer according to the child's selected response alternatives, was percent correct responses over the total number of test trials.

Morphological awareness was assessed using the Jeu de verbes task (Marquis, Royle, Gonnerman, \& Rvachew, 2012). This task used an interactive open source application developed for this task and presented on an Android tablet. The application presents children with storybook images, and requires children to complete a story by answering a question asked by the experimenter. The images and audio stimuli presented were intended to induce past tense verb production; for example an English translation of one item is as follows: "Marie is going to hide her dolls. Marie always hides her dolls. What did Marie do yesterday?" The test is designed to sample production of past participle verb forms (in the compound passé composé, perfect past, tense, e.g., Elle a caché, she AUX.3ps hide-pp 'she hid') with different regular or sub-regular endings (-é [e], $-i[\mathrm{i}],-u[\mathrm{y}])$ as well as irregular forms (e.g., mort [тэь] 'dead'). The different verb types were pseudo-randomised within the experiment with six of each type as targets. A practice block of four verbs (one exemplar for each type) was used to train the children on the task. Corrective feedback was given to the children during the practice trials, but not in the experimental block. The application recorded all of the child's verbal responses, as well as the elapsed time for viewing each image. During the experiment, the child held the tablet with the images and could observe and touch the images at will. The experimenter read the sentences with the target verbs to induce the production of the past tense in French. The experimenter moved to the next frame if the child did not respond and her silence became uncomfortable, after about 20 seconds. Regardless of the production, the child was encouraged for his/her efforts. The child's score was the number of correct responses out of a total 24 test trials for the long version administered to the kindergarten children. The short version administered to the children in grade one included only 10 items.

Finally, teachers were asked to make a prediction about each student's likelihood of developing spelling difficulties. To obtain these predictions, teachers completed a twopart questionnaire. The first question asked: "According to you, is this child at risk of 
developing spelling difficulties?" to which the teachers were to respond yes or no for each of their students. Secondly, the teachers were asked: "Based on your experience, to what degree is this child at risk for developing spelling difficulties?" and for each of their students, the teachers provided one of the following ratings: (1) no risk; (2) slight risk; (3) moderate risk; (4) strong risk; (5) extreme risk. These risk assessments are the outcome measure in Experiment 1, and these same ratings are used to predict spelling performance in Experiment 2.

\section{Results and Discussion}

Three analyses were conducted to identify variables that were associated with the teachers' predictions about their students' risk for experiencing future difficulties with the acquisition of writing skills. First, the characteristics of children deemed to be at risk were compared to the characteristics of children deemed to be not at risk. Second, linear regression was used to examine the variance in teacher ratings that was explained by the variables that appeared to be most associated with risk status, following from the first analysis. Finally, logistic regression was used to identify predictors of those children deemed to be most at risk.

When presented with a dichotomous choice, teachers identified a surprisingly large proportion of the sample as being potentially at risk for future problems in the acquisition of writing, specifically $40 \%$ of the total sample. Table 1 presents the characteristics of these children in relation to the remaining $60 \%$ deemed "not at risk" with respect to the categorical variables gender, language background and developmental status. A chi-square test revealed no reliable association between the child's gender and risk status as judged by the teacher. Language background, as determined from the parent interview, was categorized as monolingual first language French (ML) for those children who were exposed to French at least $90 \%$ of the time continuously from birth. The remaining children were simultaneous bilinguals or had been exposed to French for the first time at school entry; these children were all classified in the category multilingual (MUL) French, including both simultaneous and sequential learners of French with another language. Language background was significantly associated with teacher rating as shown in Table 1, with half of the MUL children deemed at risk compared to a third of the ML children. Parental and teacher reports identified 21 (19\%) of the children with developmental concerns. These concerns included suspected difficulties with hearing (3), attention (3), fine motor coordination (4), language development (1), anxiety (1), reading (3) and sucking/feeding (2) as well as one confirmed case of hearing impairment, one confirmed case of autism, one confirmed case of Down Syndrome and one child with a congenital heart malformation. These developmental concerns were not significantly associated with the teachers' risk ratings however. 
Table 1

Relationship Between Child's Risk Status and Categorical Predictors

\begin{tabular}{|c|c|c|c|c|c|c|c|c|}
\hline \multirow{2}{*}{\multicolumn{2}{|c|}{ Predictor }} & \multicolumn{2}{|c|}{ Not At Risk } & \multicolumn{2}{|c|}{ At Risk } & \multicolumn{3}{|c|}{ Pearson Chi-Square } \\
\hline & & $n$ & $\%$ & $n$ & $\%$ & $\chi^{2}$ & $d f$ & $p$ \\
\hline \multirow[t]{3}{*}{ Gender } & & & & & & 1.54 & 1 & .215 \\
\hline & Boys & 27 & 24 & 23 & 21 & & & \\
\hline & Girls & 40 & 36 & 21 & 19 & & & \\
\hline \multirow[t]{3}{*}{ Language Background } & & & & & & 5.16 & 1 & .023 \\
\hline & ML & 45 & 40 & 20 & 18 & & & \\
\hline & MUL & 22 & 18 & 24 & 22 & & & \\
\hline \multicolumn{4}{|c|}{ Developmental Concerns } & & & 1.82 & 1 & .177 \\
\hline $\mathrm{No} C$ & ncerns & 56 & 51 & 32 & 29 & & & \\
\hline Diagnosed or su & pected & 10 & 9 & 11 & 10 & & & \\
\hline
\end{tabular}

Table 2 compares the two risk groups on the remaining predictors with independent $t$-tests for significant differences between children who were deemed at risk versus not at risk for future difficulties with writing by their teachers. Parental education, maternal education in particular, differentiated risk status, suggesting that teachers take differences in family background into account when making their judgements, or that parental education influences child performance on variables that lead to teacher concern about the child's future performance. Other case history variables did not reach statistical significance. The number of risk factors identified by parents (i.e., birth, developmental or health difficulties) were not significantly different across the two groups and the children deemed to be at risk by teachers did not have more first degree relatives with a reported history of speech, language or literacy impairments. The home literacy questionnaire revealed that parents of children deemed not at risk were more likely to read to their children frequently and explicitly teach their child reading and writing related skills, when compared to the responses of parents whose children were rated to be at risk. All four measures of oral language skills - specifically, speech perception, phonological awareness, speech articulation accuracy, and morphological awarenessyielded significantly different scores across the two risk groups. The children's scores on these measures were regressed on age and expressed as standardized residuals in order to control for differences in chronological age within the sample. Therefore, on Table 2, a score of 0 would be the mean for the full sample, and the scores observed for the at-risk group are all below average with the lowest score observed for phonological awareness. The schools attended by these children actively taught phonological awareness skills in kindergarten, and it is not surprising that the teacher ratings would be strongly associated with a skill that they would have ample opportunity to observe and that is closely associated with both oral and written language skills. 
Table 2

Relationship Between Child's Risk Status and Predictors Measured on an Ordinal or Continuous Scale

\begin{tabular}{|c|c|c|c|c|c|c|c|c|c|}
\hline \multirow[t]{2}{*}{ Predictor } & \multicolumn{3}{|c|}{ Not At Risk } & \multicolumn{3}{|c|}{ At Risk } & \multicolumn{3}{|c|}{ Independent $t$-test } \\
\hline & $n$ & $M$ & $S D$ & $n$ & $M$ & $S D$ & $t$ & $d f$ & $p$ \\
\hline \multicolumn{10}{|l|}{ Socioeconomic indicator } \\
\hline Maternal education (years) & 66 & 14.85 & 1.87 & 43 & 13.91 & 1.90 & 2.56 & 107 & .012 \\
\hline Paternal education (years) & 65 & 14.71 & 2.13 & 43 & 14.00 & 1.83 & 1.79 & 106 & .077 \\
\hline \multicolumn{10}{|l|}{ Case History Report } \\
\hline Number of risk factors reported & 66 & 1.61 & 1.78 & 43 & 2.14 & 2.23 & -1.38 & 107 & .170 \\
\hline Strength of family history & 64 & 0.42 & 0.66 & 43 & 0.40 & 0.70 & 0.20 & 105 & .842 \\
\hline \multicolumn{10}{|l|}{ Home Literacy Questionnaire } \\
\hline Shared Reading Frequency & 66 & 3.73 & 0.80 & 43 & 3.42 & 0.73 & 2.04 & 107 & .043 \\
\hline Emergent Literacy Activities & 66 & 2.95 & 1.10 & 43 & 3.02 & 1.03 & -0.33 & 107 & .745 \\
\hline Reading/writing teaching & 66 & 3.14 & 0.89 & 43 & 2.70 & 0.96 & 2.42 & 107 & .017 \\
\hline \multicolumn{10}{|l|}{$\underline{\text { Language assessment results }}$} \\
\hline Speech perception & 67 & 0.17 & 0.81 & 44 & -0.27 & 1.20 & -2.27 & 109 & .025 \\
\hline Phonological awareness & 67 & 0.33 & 0.78 & 44 & -0.51 & 1.09 & -4.78 & 109 & .000 \\
\hline Speech Articulation Accuracy & 67 & 0.29 & 0.83 & 44 & -0.39 & 1.05 & -3.82 & 109 & .000 \\
\hline Morphological awareness & 67 & 0.15 & 0.91 & 42 & -0.25 & 1.10 & -2.08 & 107 & .040 \\
\hline
\end{tabular}

A second analysis examined how well maternal education and oral language test performance predicted the teachers' ratings when considering the 5 point scale, indicating the degree to which teachers thought the child might encounter difficulties with writing in the future. The numbers (percent) of ratings in each category were as follows: $64(56 \%)$ no risk; 21 (18\%) slight risk; 12 (11\%) moderate risk; $9(8 \%)$ strong risk; and $5(4 \%)$ extreme risk. The distribution is clearly skewed and therefore a logarithmic transformation was applied to improve the distribution, although the transformed scores did not achieve a normal distribution due to the severity of the skew toward "no risk". Nonetheless, a two-step hierarchical multiple linear regression was applied in order to assess the contribution of home background variables and children's oral language test performance to the teacher ratings of risk. The results of this analysis, shown in Table 3, indicate that the home background variables (maternal education, frequency of home literacy activities, frequency of literacy teaching at home) accounted for $9.5 \%$ of variance in the teacher rating while the children's language test scores explained an additional $27 \%$ of variance in the teacher ratings, with the coefficients being statistically significant for the children's speech perception, speech production and phonological awareness test performance. 
Table 3

Hierarchical Multiple Regression Analysis Predicting Teacher Ratings of Literacy Risk on 5-Point Scale With Home Background Variables and Child Oral Language Performance

\begin{tabular}{lll}
\hline Predictor & $\Delta R^{2}$ & $\beta$ \\
\hline Step 1 & $.095^{*}$ & \\
Maternal education & & -.19 \\
Home literacy activities & -.14 \\
Home literacy teaching & -.11 \\
Step 2 & $.23^{* *}$ & \\
Maternal education & & -.14 \\
Home literacy activities & -.08 \\
Home literacy teaching & .01 \\
Morphological awareness & -.07 \\
Speech articulation accuracy & $-.20^{*}$ \\
Speech perception & $-.20^{*}$ \\
Phonological awareness & $-.33^{* *}$ \\
Total $R^{2}=.32$ & \\
$n=107$ & \\
\hline$* p<.05 * * p<.001$ &
\end{tabular}

Finally, we compared the predictive power of the variables that we previously identified as being associated with teacher predictions. We used a logistic regression analysis to predict risk status from maternal education and the measures of oral language performance. For this analysis, risk status was dichotomized, with children being categorized as either "Most at risk" (ratings 4 and 5), or "Least at risk" (ratings 1, 2, and 3 ). This analysis resulted in an overall classification accuracy of $90.8 \%$, correctly identifying $98 \%$ of the children least at risk, but only $43 \%$ of the children most at risk. As seen in Table 4, the overall model significantly predicted risk status, with maternal education, phonological awareness test performance and speech articulation accuracy providing a significant independent contribution to the teacher ratings, while the remaining language tests did not.

In summary, these analyses show that teachers rate a large proportion of their school entry students at some risk of future difficulties with the acquisition of literacy skills and approximately $12 \%$ of them at strong or extreme risk. These ratings are associated with characteristics including the mother's education level and the child's speech accuracy and phonological awareness skills. Home literacy practices also appear to make a small contribution. Identifying the factors that contribute to teachers' ratings, as we have done in Experiment 1, is an important step towards gaining a better understanding of the utility of teachers' assessments for identifying children at-risk for spelling problems. However, if teacher ratings are to be used effectively in the screening process, they must also be accurate at identifying at-risk children. In Experiment 2, we test the accuracy and validity of the ratings provided by teachers in Experiment 1. 
Table 4

Logistic Regression Analysis Predicting Risk Status (Most at Risk or Least at Risk) With Maternal Education and Child Oral Language Performance

\begin{tabular}{|c|c|c|c|c|}
\hline Predictor & $B$ & $S E$ & Wald & $\operatorname{Exp}(B)$ \\
\hline Maternal Education & -.14 & .21 & .46 & .87 \\
\hline $\begin{array}{l}\text { Speech articulation } \\
\text { accuracy }\end{array}$ & -.48 & .32 & 2.23 & .62 \\
\hline Speech perception & -.87 & .34 & 6.54 & $.42 *$ \\
\hline $\begin{array}{l}\text { Phonological } \\
\text { awareness } \\
\text { Model } \chi^{2}=29.57^{* * *} \\
\text { Nagelkerke } R^{2}=.44 \\
n=109\end{array}$ & -1.13 & .40 & 8.02 & $.32 * *$ \\
\hline
\end{tabular}

Experiment 2

Having gained a better understanding of the basis for teachers' assessments in Experiment 1, we will now turn our attention to determining the accuracy of these assessments. The purpose of Experiment 2 was to evaluate the predictive validity of the teachers' ratings from the first experiment. With the children's spelling performance as the outcome measure, we were able to examine the strength of the relationship between the teachers' predictions and the students' actual performance. Moreover, we were able to compare the predictive power of teachers' ratings to the other social and developmental factors measured in Experiment 1 for predicting the children's future spelling ability. Not only will the present study assess factors that influence teachers' judgements, but it will also determine the degree to which these judgements are accurate.

\section{Method}

Participants. A subset of the children $(n=39)$ described in Experiment 1 were administered a spelling test a year later at the end of the grade one year. The children included were those for whom we had complete data and teacher ratings from the previous year and for whom we had parental permission to get spelling test data in the second year. The assessment served the purpose of piloting procedures and training staff in preparation for the final outcome assessments planned for the end of second grade. Among these 39 children were 18 judged to be not at risk by their teachers based on the data from the kindergarten assessment in Experiment 1. This subsample contained 6 boys and 6 MUL learners; the remaining 21 children deemed at risk included 12 boys and 9 MUL learners; all of these children were first assessed at the end of the kindergarten year.

Procedures. At the end of the grade one the Batterie d'évaluation de lecture et d'orthographe (BELO; Pech-Georgel \& George, 2006) was administered to the children in small groups of 3 or 4 , in order to assess the children's spelling ability. This task was chosen because it is adapted to the age level and language of our participants and evaluates phono-orthographic abilities (non-word syllables), basic orthographic abilities 
for known words (real words) and basic syntax and morphosyntactic abilities (sentences). It is the only task presently available for French that can evaluate writing in the age group we targeted. The task is divided into three sections: the first is a novel-word spelling task (with 5 one-syllable, e.g., fir, and 5 two-syllable items, e.g., palon), the second is a regular word spelling task that assesses both phonological and orthographic processes (with 10 frequent and 5 low-frequency items with simple, e.g., fam in famille 'family', complex, e.g., ille in famille, and contextual grapho-phonemic correspondences, e.g., $g$ in rouge [виз] 'red') and the third is a sentence-writing task (4 multiple word sentences for a total of 35 items). A standard dictation procedure was used in which the examiner presented the items live-voice and the children were asked to write down what they heard on paper marked with familiar primary school line markings. The test is not timed and therefore each item was presented when the entire group had completed their transcription of the previous item. The final score was calculated as the percentage of words spelled completely and correctly.

\section{Results and Discussion}

A linear regression analysis showed that the transformed 5-point teacher prediction scores predicted $44 \%$ of variance in grade one BELO scores, $F(1,38)=29.38$, $p<.001$. Figure 1 illustrates a strong negative gradient with those children deemed most at risk at the end of kindergarten achieving the lowest scores on the spelling test at the end of grade one. In contrast, maternal education predicted only $9 \%$ of unique variance in grade one BELO scores, $F(1,38)=3.50, p=.069$. Altogether, the four measures of oral language skills, administered in kindergarten, predicted $24 \%$ of variance in grade one BELO scores, $F(1,38)=2.67, p=.049$. Using a hierarchical analysis, teacher predictions account for an additional $28 \%$ of variance in grade one BELO scores, as shown in Table 5. This result indicates that teacher predictions contribute a unique perspective, and not simply overlapping information, in relation to standard testing of the children's abilities. At the same time, the objective measures of the children's oral language skills and the teacher's ratings together provided the best prediction, with $52 \%$ of variance in spelling performance explained in total. 


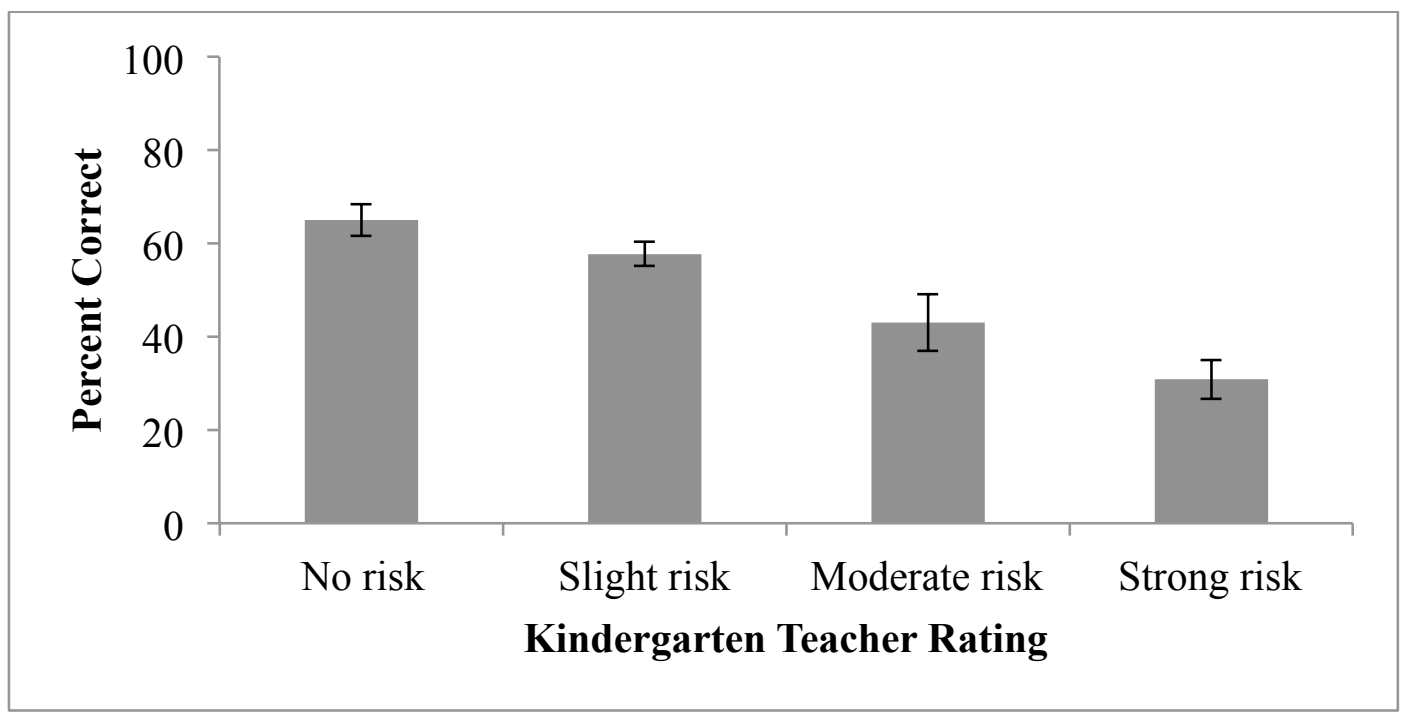

Figure 1. Percent correct on the BELO test of spelling ability measured in grade one by teacher's risk rating provided in Kindergarten.

Table 5

Hierarchical Multiple Regression Analysis Predicting Spelling Performance as Measured by the BELO with Teacher Ratings of Literacy Risk and Child Oral Language

Performance

\begin{tabular}{|c|c|c|}
\hline Predictor & $\Delta R^{2}$ & $\beta$ \\
\hline Step 1 & $.24 *$ & \\
\hline Morphological awareness & & .14 \\
\hline Speech articulation accuracy & & .16 \\
\hline Speech perception & & .16 \\
\hline Phonological awareness & & $.40^{*}$ \\
\hline Step 2 & $.28 * *$ & \\
\hline Teacher ratings & & $-.61 * *$ \\
\hline Morphological awareness & & .19 \\
\hline Speech articulation accuracy & & -.04 \\
\hline Speech perception & & .11 \\
\hline Phonological awareness & & .15 \\
\hline $\begin{array}{l}\text { Total } R^{2}=.52 \\
n=41\end{array}$ & & \\
\hline
\end{tabular}

In terms of the ability to identify those children most at risk, this preliminary sample was too small for formal calculation of sensitivity and specificity data. However, we examined the characteristics of the four children with the lowest BELO scores (i.e., $10 \%$ of the sample) and found that all four of these children were rated by their teachers to be "at-risk", with either a "moderate" or "strong" risk rating. Maternal education was 
low on average with 3 of the 4 mothers achieving only a high-school diploma. The four children with the lowest BELO scores were ML learners of French but all had difficulty on the measures of oral language ability. Specifically, three had significant difficulties on the phonological awareness test, being unable to identify the picture of the word that rhymed with a target name (e.g., Guy [gi] = scie [si] 'saw' vs feu [fø] 'fire', chat [fa] 'cat', but [by] 'goal'); the fourth child passed the phonological awareness test but had difficulties with, specifically being unable to produce the past tense of verbs requiring non-default passé composé forms (e.g., il a mordu [товdy] 'he bit', or elle a fini [fini] 'she finished') although he was able to complete the task with the default $-\dot{e}$ first conjugation forms (e.g., elle a caché [kaje] 'she hid').

Another group of interest would be those children who were rated at-risk by their teachers but who achieved relatively good BELO scores. Two children fit this profile and both were MUL learners of French, indicating that predicting future learning difficulties may be more complicated in the case of children with multilingual exposure. Alternatively, school programs that target the needs of these students may facilitate the acquisition of accurate spelling skills in elementary school.

Finally, one child deemed to be not at-risk was observed to have poor spelling performance at the end of grade one (percentile rank 20). This child was an MUL learner of French whose mother was exceptionally well educated. The child also had severe difficulties with consonant articulation and low scores on the tests of phonological awareness and morphological awareness. These oral language difficulties may have been masked by the child's second language status but ultimately may be significant indicators of a language and literacy learning impairment that requires further investigation.

\section{General Discussion}

This study explored the information that teachers take into account when making judgments about their students' literacy skills, and isolated the factors that contribute most to these assessments when the outcome measure is French children's spelling ability. Furthermore, this study evaluated the predictive validity of the teachers' ratings, comparing teachers' ratings given in kindergarten to children's actual spelling performance measured in grade one. We found that language background, the education level of mothers, home literacy practices, and oral language skills all differentiated whether or not the children were identified by their teachers as being at-risk for future writing difficulties. We determined that while both contributed significantly to teacher's predictions, the children's oral language skills accounted for even more of the variance in the teacher ratings than the home background information. Finally, we showed that teacher ratings were relatively accurate for predicting children's future writing ability; furthermore, the ratings explained unique variance in spelling outcomes, over and above measures of oral language skill.

Previous research has established that oral language skills, including phonological (Adams, 1990; Wagner \& Torgesen, 1987) and morphological awareness ability (Deacon \& Kirby, 2004; Nagy et al., 2006), speech errors (Nathan et al., 2004) and immature grammar (Catts et al., 2001) are strong predictors of future reading and writing performance. Our study provides evidence that these abilities also contribute to teachers' predictions of their students' risk for writing problems. Each of our measures of oral language (speech perception, phonological awareness, speech articulation accuracy and 
morphological awareness) significantly differed according to the children's risk status as judged by their teachers. These findings are consistent with other evidence suggesting that teachers are in fact good at judging oral language processing (e.g., Duff, Mengoni, Bailey, \& Snowling, 2014). Importantly, children in these schools were actively taught phonological processing, which may have heightened the teachers' sensitivity to children's phonological awareness abilities, making them more easily observed in the classroom. These results suggest that teachers are not just sensitive to their students' oral language abilities; they are also able to use this information to predict their student's risk of literacy difficulty.

Beyond oral language performance, teachers may also consider background characteristics of their students when making their assessments, including maternal education and home literacy environment. Similar to Beswick et al. (2005), we found that maternal education was associated with teacher ratings. Additionally, our results indicate that children's home literacy environment was related to the teacher's assessments, such that children who were predicted to be not at-risk for later writing difficulties reportedly experienced more shared reading and home teaching of literacy skills than children judged as at-risk. Our findings suggest that teachers may have some knowledge of parental education and home literacy practices, and that they are using this information in their assessments. However, it is not clear from the present study whether teachers are directly aware of either the education level of parents, or the home literacy environment. Alternatively, it is possible that the relationship between these variables and the teacher ratings is an indirect one, emerging from the relationship between literacy skills and both parental education (Bowey, 1995), and the home literacy environment (Mol \& Bus, 2011). Future studies should seek to elucidate the interrelationship between home literacy, parental education and literacy skills, and the influence of these variables on teacher's assessments.

A child's language background was additionally shown to be associated with risk status. Specifically, as compared to monolingual French speakers, more children were designated as being at-risk for writing problems if their first language was not French, or if they learned another language simultaneously with French. The language background of a child may be readily accessible to a teacher, and it is likely apparent if a child's first language is not the dominant language within a school. Bilingual children can show early delays in oral language skills in their second language (Durgunoğlu, Nagy, \& HancinBhatt, 1993), and it seems that teachers are sensitive to this characteristic when they are making their assessments. However, despite these differences early in development, evidence indicates that bilingualism does not have a negative impact on all aspects of children's literacy ability, especially basic decoding and spelling skills (e.g., SaieghHeddad \& Geva, 2010). So if teachers base their assessment only on the presence of delays in second language early in development, this may lead to inaccuracy in their assessment of later literacy skills.

The developmental concerns reported by the parents in our study were not related to the teacher's ratings of risk status. This is surprising, as it seems intuitive that the child's developmental concerns, including language and reading concerns, would be highly associated with later writing difficulty. However, in our study, many of the concerns reported may not be readily apparent to teachers. While teachers may be aware of the language difficulties their students are experiencing, the developmental concerns 
also included factors that may not be easily known by teachers, or may not be intuitively associated with literacy development (e.g., fine motor coordination, anxiety, and sucking and feeding difficulties). Similarly, the fact that a history of language problems within the child's family was not associated with risk status likely reflects the fact that this information is not easily observed by teachers. Together, these findings suggest that teachers are relying primarily on information that is known and accessible to them in a typical classroom, and less on other factors that may be highly informative but are less easily observed.

Having identified the factors associated with teacher predictions, we were able to compare the relative strength of these factors for predicting teacher ratings. Based on our analysis, we determined that oral language factors were the strongest predictors of teacher ratings, especially phonological awareness. This is an encouraging finding, as it suggests that the factors that are most strongly related to teacher ratings are in fact the best predictors of literacy ability. The home background variables, also predicted teacher ratings, providing further evidence that teachers are accounting for the most informative factors when making their assessments of students' future risk for literacy difficulty.

Finally, our study provides support for the notion that teachers are accurate at predicting the literacy skills of their students. Not only were the teacher ratings predictive of children's later spelling performance, the contribution of these ratings was independent from the oral language measures. We also found that the students with the lowest scores on the spelling test were in fact rated by their teachers as at-risk, and these children also had displayed risk factors including mothers with low education and difficulty on the oral language tests. Thus, it seems that teachers are effective at selecting children who are atrisk for future literacy difficulty.

While overall, teachers were accurate in their assessments; we found that there was some degree of inaccuracy. There were two children who were rated at-risk by their teachers, but who displayed relatively good spelling scores. These two children were also MUL learners of French. Recall that we found that teachers are relying on early delays in oral language processing in their assessments. However, as previously discussed, bilingualism does not necessarily lead to later literacy difficulties (Saiegh-Haddad \& Geva, 2010). Thus, bilingualism appears to complicate teacher judgements of children's potential for later literacy acquisition. Making teachers aware of the children's language profiles, and the nuances of literacy development for bilingual children may improve their accuracy in the identification of children most at risk for delayed acquisition of literacy skills.

Finally, the teachers showed inaccuracy on a particularly interesting case of one child who was given a rating of no-risk, and who later showed poor spelling performance. While this child was an MUL learner of French and his mother had a high level of education, this child performed very poorly on some of the oral language skills measured, and ultimately achieved a relatively low score on the BELO measure of spelling ability at the end of grade one. The discrepancy between the teacher's impression and the child's test performance may be due to the interaction of social and biological risk and protective factors in this case. Thomas and Knowland (2014) modeled the mechanisms of resolving and persisting delay in language development, and concluded that distinct causal mechanisms underlie these developmental trajectories. More specifically, they provide evidence that environmental factors impacted language outcomes in the group that 
demonstrated typical development and the group that demonstrated resolving delay; on the other hand, the persisting delay trajectory was not influenced by environmental inputs, because limitations on the ability to process those inputs (limitations that presumably have genetic origins) constrain learning from a rich language learning environment even when present. This outcome was observed in both the computer modeling data and in the real data sets that were examined in this paper. Given that teachers appear to combine both social factors and children's performance across a broad range of behavioral and academic domains when predicting risk for delays in the acquisition of literacy skills, the prediction anomalies that we identified in this report make sense. Children who are sensitive to strong environmental inputs may show a resolving trajectory of language development and therefore not meet the expectations of slower acquisition; at the same time, children with no social risk factors may not be recognized as having significant biological risk for language and literacy delay. For these reasons, objective measures of language and emergent literacy skills continue to be advisable despite the overall excellent performance of the teachers in this report with respect to prediction accuracy.

\section{Future Directions}

In addition to providing insight into the basis of teacher ratings, the present study offers potential opportunities for future research. The current report covers predictions and outcomes for only a very short time interval, approximately 6 to 8 months, and it is important that future research establishes that teachers or objective tests are accurate at predicting literacy outcomes over the longer term. Moreover, the factors that influence teacher ratings, and their relative contributions, may not remain stable across development. Additionally, this study was run on a small sample including 9 teachers in total, so it is unclear whether they were representative of a normal sample or not. Thus, future studies should examine which factors contribute to teacher ratings over a longer period of a time, as well as the long-term accuracy of these ratings and their stability over a larger number of assessors. Finally, further research is needed to explore the intricacies of interrelationships between the factors that contribute to teachers' ratings. Specifically, it will be important to clarify whether home literacy practices and maternal education contribute to teacher ratings directly, or indirectly through their relationship with other literacy-related skills. In addition, future research should explore the degree to which teachers are sensitive to the interrelationships between language background, maternal education and oral language abilities, and whether or not teachers' perceptions of these relationships lead to inaccuracy in their assessments.

\section{Conclusion}

The ultimate goal of this work was to determine the degree to which teacher predictions can be used effectively for the early identification of children at-risk for literacy problems. Having identified the factors contributing to teachers predictions, it seems that their assessments are associated to the most relevant and informative predictors of literacy skills; namely oral language abilities, maternal education, and home literacy practices. Furthermore, teachers in this study predicted children's risk for spelling difficulties with a great deal of accuracy, although some inaccuracies emerged primarily with respect to their assessments of children from multilingual backgrounds. The greatest 
amount of accuracy is achieved when teacher ratings are combined with standardized testing measures. Taken together, our findings suggest that teacher ratings are effective and efficient for providing an early indicator of children who may be at risk for later literacy difficulty.

\section{Acknowledgements}

This research was supported by research grant FQRSC 2011-ER-144359 awarded to authors Rvachew, Gonnerman and Royle. We are also grateful for various material and financial supports from the Centre for Research in Brain, Language and Music. We are thankful to the schools, children and parents who participated in this project. Finally we acknowledge the research assistance provided by many students especially Catherine Lamirande, Madeleine Bellemare, Catherine Clémence, Tara Commandeur, and Geneviève Beauregard-Paultre.

\section{References}

Adams, M. J. (1990). Beginning to read: Thinking and learning about print. Cambridge, MA: MIT Press.Baker, L., Scher, D., \& Mackler, K. (1997). Home and family influences on motivations for reading. Educational Psychologist, 32(2), 69-82.

Beswick, J. F., Willms, J. D., \& Sloat, E. A. (2005). A comparative study of teacher ratings of emergent literacy skills and student performance on a standardized measure. Education, 126(1), 116-137.

Bialystok, E., McBride-Chang, C., \& Luk, G. (2005). Bilingualism, language proficiency, and learning to read in two writing systems. Journal of Educational Psychology, 97(4), 580.

Bird, J., Bishop, D. V. M., \& Freeman, N. H. (1995). Phonological awareness and literacy development in children with expressive phonological impairments. Journal of Speech and Hearing Research, 38, 446-462.

Bowey, J. A. (1995). Socioeconomic status differences in preschool phonological sensitivity and first-grade reading achievement. Journal of Educational Psychology, 87(3), 476-487.

Bradley, L., \& Bryant, P. (1991). Phonological skills before and after learning to read. In S. A. Brady and D. P. Shankweiler (Eds.), Phonological processes in literacy: A tribute to Isabelle Y. Liberman (pp. 37-45). Hillsdale, NJ: Erlbaum.

Brosseau-Lapré, F., \& Rvachew, S. (2008). Test de Conscience Phonologique Préscolaire, unpublished test, McGill University.

Bruchmüller, K., Margraf, J., \& Schneider, S. (2012). Is ADHD diagnosed in accord with diagnostic criteria? Overdiagnosis and influence of client gender on diagnosis. Journal of Consulting and Clinical Psychology, 80(1), 128.

Buckingham, J., Bearman, R., \& Wheldall, K. (2014). Why poor children are more likely to become poor readers: The early school years. Educational Review, 66, 428446.

Catts, H. W. (1991). Early identification of reading disabilities. Topics in Language Disorders, 12(1), 1-16. 
Catts, H. W., Fey, M. E., Zhang, X., \& Tomblin, J. B. (2001). Estimating the risk of future reading difficulties in kindergarten children: A research-based model and its clinical implementation. Language, Speech, and Hearing Services in Schools, 32, 38-50.

Chiu, M. M., \& McBride-Chang, C. (2006). Gender, context, and reading: A comparison of students in 43 countries. Scientific Studies of Reading, 10(4), 331-362.

Connor, C. M., Alberto, P. A., Compton, D. L., \& O'Connor, R. E. (2014). Improving Reading Outcomes for Students with or at Risk for Reading Disabilities: A Synthesis of the Contributions from the Institute of Education Sciences Research Centers. NCSER 2014-3000. National Center for Special Education Research.

Council of Ministers of Education, Canada. (2009). Key factors to support literacy success in school-aged populations: A literature review. Retrieved from http://www.cmec.ca/Publications/Lists/Publications/Attachments/201/key-factorsliteracy-school-aged.pdf

Deacon, S. H., \& Kirby, J. R. (2004). Morphological awareness: Just "more phonological'? The roles of morphological and phonological awareness in reading development. Applied Psycholinguistics, 25(02), 223-238.

Duff, F. J., Mengoni, S. E., Bailey, A. M., \& Snowling, M. J. (2014). Validity and sensitivity of the phonic screening check: Implications for practice. Journal of Research in Reading, 38(2), 109-123.

Durgunoğlu, A. Y., Nagy, W. E., \& Hancin-Bhatt, B. J. (1993). Cross-language transfer of phonological awareness. Journal of Educational Psychology, 85(3), 453-465.

Feinberg, A. B., \& Shapiro, E. S. (2009). Teacher accuracy: An examination of teacherbased judgments of students' reading with differing achievement levels. The Journal of Educational Research, 102(6), 453-462.

Gijsel, M. A., Bosman, A. M., \& Verhoeven, L. (2006). Kindergarten risk factors, cognitive factors, and teacher judgments as predictors of early reading in Dutch. Journal of Learning Disabilities, 39(6), 558-571.

Glover, T. A., \& Albers, C. A. (2007). Considerations for evaluating universal screening assessments. Journal of School Psychology, 45(2), 117-135.

Hampden-Thompson, G. (2013). Family policy, family structure, and children's educational achievement. Social Science Research, 42(3), 804-817.

Harm, M. W., McCandliss, B. D., \& Seidenberg, M. S. (2003). Modeling the successes and failures of interventions for disabled readers. Scientific Studies of Reading, $7(2), 155-182$.

Hecht, S. A., Burgess, S. R., Torgesen, J. K., Wagner, R. K., \& Rashotte, C.A. (2000). Explaining social class differences in growth of reading skills from beginning kindergarten through fourth-grade: The role of phonological awareness, rate of access, and print knowledge. Reading and Writing: An Interdisciplinary Journal, 12, 99-127.

Hecht, S. A., \& Greenfield, D. B. (2001). Comparing the predictive validity of first grade teacher ratings and reading-related tests on third grade levels of reading skills in young children exposed to poverty. School Psychology Review, 30, 50-69.

Joanisse, M. F., Manis, F. R., Keating, P., \& Seidenberg, M. S. (2000). Language deficits in dyslexic children: Speech perception, phonology, and morphology. Journal of Experimental Child Psychology, 77, 30-60. 
Kettler, R. J., \& Albers, C. A. (2013). Predictive validity of curriculum-based measurement and teacher ratings of academic achievement. Journal of School Psychology, 51(4), 499-515.

Leppänen, U., Niemi, P., Aunola, K., \& Nurmi, J.-E. (2004). Development of reading skills among preschool and primary school pupils. Reading Research Quarterly, 39(1), 72-93.

Levin, I., Ravid, D., \& Rapaport, S. (2001). Morphology and spelling amoung Hebrewspeaking children: From kindergarten to first grade. Journal of Child Language, 28(3), 741-772.

Lewis, B. A., Freebairn, L. A., \& Taylor, H. G. (2000). Follow-up of children with early expressive phonology disorders. Journal of Learning Disabilities, 33(5), 433-444.

Lewis, B. A., O'Donnell, B., Freebairn, L., \& Taylor, H. G. (1998). Spoken language and written expression - interplay of delays. American Journal of Speech-Language Pathology, 7, 77-84.

Marquis, A., Royle, P., Gonnerman, L. M., \& Rvachew, S. (2012). La conjugaison du verbe en début de scolarisation. TIPA. Travaux Interdisciplinaires sur la Parole et le Langage [On-line publication], 28. http://tipa.revues.org/201

McGeown, S. P., Duncan, L. G., Griffiths, Y. M., \& Stothard, S. E. (2014). Exploring the relationship between adolescent's reading skills, reading motivation and reading habits. Reading and Writing, 28(4), 545-569.

Ministère de l'Éducation, du Loisir et du Sport [MELS] (2012). Terms and conditions for obtaining a Quebec teaching license. Retrieved from http://www.mels.gouv.qc.ca/fileadmin/site_web/documents/reseau/formation_titul arisation/PermisEnseignerHorsQuebec_Juillet2012_a.pdf

Ministère de l'Éducation, du Loisir et du Sport [MELS] (2013). Français, langue d'enseignement. Retrieved from http://www1.mels.gouv.qc.ca/progressionPrimaire/francaisEns/index.asp?page $=\mathrm{c}$ ompEcrire

Mol, S. E., \& Bus, A. G. (2011). To read or not to read: a meta-analysis of print exposure from infancy to early adulthood. Psychological Bulletin, 137(2), 267.

Nagy, W., Berninger, V. W., \& Abbott, R. D. (2006). Contributions of morphology beyond phonology to literacy outcomes of upper elementary and middle-school students. Journal of Educational Psychology, 98(1), 134.

Nathan, L., Stackhouse, J., Goulandris, N., \& Snowling, M. J. (2004). The development of early literacy skills among children with speech difficulties: A test of the "critical age hypothesis". Journal of Speech, Language, and Hearing Research, 47, 377-391.

Overby, M., \& Bernthal, J. E. (2008). A study of speech sound perception and phonological spelling in children with SSD. Paper presented at the American Speech-Language-Hearing Association, Chicago, IL.

Ouellette, G., \& Senechal, M. (2008). Pathways to literacy: A study of invented spelling and its role in learning to read. Child Development, 79, 899-913.

Pacton, S., \& Deacon, S. H. (2008). The timing and mechanisms of children's use of morphological information in spelling: A review of evidence from English and French. Cognitive Development, 23, 339-359. 
Pech-Georgel, C., \& George, F. (2006). BELO: Batterie d'évaluation de lecture et d'orthographe. Marseille: Éditions Solal.

Pennala, R., Eklund, K., Hämäläinen, J., Richardson, U., Martin, M., Leiwo, M., Leppänen, P. H. T., Lyytinen, H. (2010). Perception of phonemic length and its relation to reading and spelling skills in children with family risk for dyslexia in the first three grades of school. Journal of Speech, Language \& Hearing Research, 53(3), 710-724.

Perfetti, C., \& Curtis, M. (1986). Development of children's reading self-concepts and their relationship with reading achievement. Journal of Educational Psychology, 87, 155-169.

Rvachew, S. (1994). Speech perception training can facilitate sound production learning. Journal of Speech and Hearing Research, 37, 347-357.

Rvachew, S., \& Grawburg, M. (2006). Correlates of phonological awareness in preschoolers with speech sound disorders. Journal of Speech, Language, and Hearing Research, 49, 74-87.

Rvachew, S., Marquis, A., Brosseau-Lapré, F., Royle, P., Paul, M., \& Gonnerman, L. M. (2013). Speech articulation performance of francophone children in the early school years: Norming of the Test de Dépistage Francophone de Phonologie. Clinical Linguistics \& Phonetics, 27(12), 950-968.

Saiegh-Haddad, E., \& Geva, E. (2010). Acquiring reading in two languages: An introduction to the special issue. Reading and Writing, 23, 263-267.

Senechal, M., LeFevre, J., Thomas, E. M., \& Daley, K. E. (1998). Differential effects of home literacy experiences on the development of oral and written language. Reading Research Quarterly, 33(1), 96-116.

Shaywitz, S. E., \& Shaywitz, B. A. (2003). Dyslexia (specific reading disability). Pediatrics in Review, 24(5), 147-153.

Sokal, L., \& Piotrowski, C. (2011). My Brother's Teacher? Siblings and Literacy Development in the Home. Education Research International, 2011. doi: $10.1155 / 2011 / 253896$

Statistics Canada (2011). Focus on Geography Series, 2011 Census. Retrieved from http://www12.statcan.gc.ca/census-recensement/2011/as-sa/fogs-spg/Facts-csdeng.cfm? $\mathrm{LANG}=$ Eng $\& \mathrm{GK}=\mathrm{CSD} \& \mathrm{GC}=2465005$

Südkamp, A., Kaiser, J., \& Möller, J. (2012). Accuracy of Teachers’ judgments of students' academic achievement: A meta-analysis. Journal of Educational Psychology, 104, 743-762.

Teisl, J. T., Mazzocco, M. M., \& Myers, G. F. (2001). The utility of kindergarten teacher ratings for predicting low academic achievement in first grade. Journal of Learning Disabilities, 34(3), 286-293.

Thomas, M. S. C., \& Knowland, V. C. P. (2014). Modeling mechanisms of persisting and resolving delay in language development. Journal of Speech, Language, and Hearing Research, 57, 467-483.

Tomblin, J. B., Zhang, X., Buckwalter, P., \& Catts, H. W. (2000). The association of reading disability, behavioral disorders, and language impairment among secondgrade children. Journal of Child Psychology and Psychiatry, 41(4), 473-482.

Torgesen, J. K. (2002). The prevention of reading difficulties. Journal of School Psychology, 40(1), 7-26. 
Wagner, R. K., \& Torgesen, J. K. (1987). The nature of phonological processing and its causal role in the acquisition of reading skills. Psychological Bulletin, 101(2), 192.

Wolf., R. M. (1997). Rating scales. In J. P. Keeves (Ed.), Educational research, methodology and measurement: An international handbook, $2^{\text {nd }}$ ed. (pp. 958-965). Adelaide: Pergamon.

Author Biographies

Kendall Kolne is a $\mathrm{PhD}$ student in the School of Communication Sciences and Disorders at McGill University. Her research focuses on the role of morphological awareness in reading and spelling development.

Laura M. Gonnerman, PhD, is an Associate Professor in the School of Communication Sciences and Disorders at McGill University.

Alexandra Marquis is an Assistant Professor in the Department of Linguistics at United Arab Emirates University. Her research areas include language acquisition, psycholinguistics, morphosyntax and bilingualism.

Phaedra Royle, professor at the École d'orthophonie et d'audiologie Université de Montréal, holds a Ph.D. in Linguistics and carries out research on language learning, psycholinguistic processing and neurolinguistic imaging in children and adults, with a focus on language-learning impairments in French populations.

Susan Rvachew, Ph.D., S-LP(C), ASHA Fellow, is a Professor in the School of Communication Sciences and Disorders at McGill University and Centre for Research in Brain, Language and Music.

\section{Appendix A}

\section{Case History Questionnaire}

\# du participant

Site de l'entrevue
ID Employé

Date

FORMULAIRE DE L'HISTOIRE DE CAS

1. Est-ce qu'il y a eu des inquiétudes ou complications durant la grossesse pour cet enfant? OUI

NON

Si oui, SVP décrire:

2. Est-ce qu'il y a eu des inquiétudes ou complications peu après la naissance de votre enfant? OUI

NON

Si oui, SVP décrire: 
3.Est-ce que la santé de votre enfant est généralement bonne?

OUI

NON

Si non, SVP décrire:

4.Est-ce que votre enfant présente une condition médicale ou a reçu un diagnostic?

OUI

NON

Si oui, SVP décrire:

5. Est-ce que votre enfant a eu un accident majeur, ou des chirurgies?

OUI

NON

Si oui, SVP décrire:

6.Est-ce que vous avez des inquiétudes à propos des habiletés motrices de votre enfant (difficultés de coordination, maladresse)?

OUI

NON

Si oui, SVP décrire:

7. Est-ce que vous avez des inquiétudes à propos de l'interaction sociale de votre enfant avec d'autres membres de la famille ou d'autres enfants?

OUI

NON

Si oui, SVP décrire:

8. Est-ce que votre enfant a déjà eu des difficultés d'alimentation (i.e. écoulement salivaire, difficultés à sucer, téter ou avaler)?

OUI

NON

Si oui, SVP décrire:

9. Est-ce que vous avez déjà soupçonné des difficultés au niveau de l'audition de votre enfant?

OUI

NON

Si oui, SVP décrire:

10. À quel âge (en mois) votre enfant a-t-il fait les choses suivantes pour la première fois? Babiller:

Premier mot:

Combiner deux mots: 
11. Avez-vous une idée de ce qui a pu causer les difficultés de parole ou de langage de votre enfant?

OUI

NON

Si oui, SVP décrire:

12. SVP cocher les membres de la famille suivants qui ont ou qui ont eu des difficultés au niveau de la parole, du langage, ou de la lecture.

Mère

Père

Fratrie

Autres

13. SVP indiquer les langues parlées à la maison et le pourcentage de temps durant lequel chaque langue est parlée.

Langue 1:

Langue 3:

$\%$ du temps

Langue 2:

Langue 4:

$\%$ du temps

$\%$ du temps

$\%$ du temps

14. Le plus haut niveau d'éducation complétées par la mère:

15. Le plus haut niveau d'éducation complétées par le père:

16. Occupation de la mère:

17. Occupation du père:

18. Est-ce que votre enfant fréquente une garderie?

OUI

NON

Si oui, SVP décrire:

19. Est-ce que votre enfant a reçu quelque thérapie que ce soit dans le passé?

OUI

NON

Si oui, SVP décrire:

20. Est-ce que votre enfant reçoit présentement des services de thérapie?

OUI

NON

Si oui, SVP décrire: 
Appendix B

Language Questionnaire

\section{LANGUAGES SPOKEN BY FAMILY}

\section{To Each Other:}

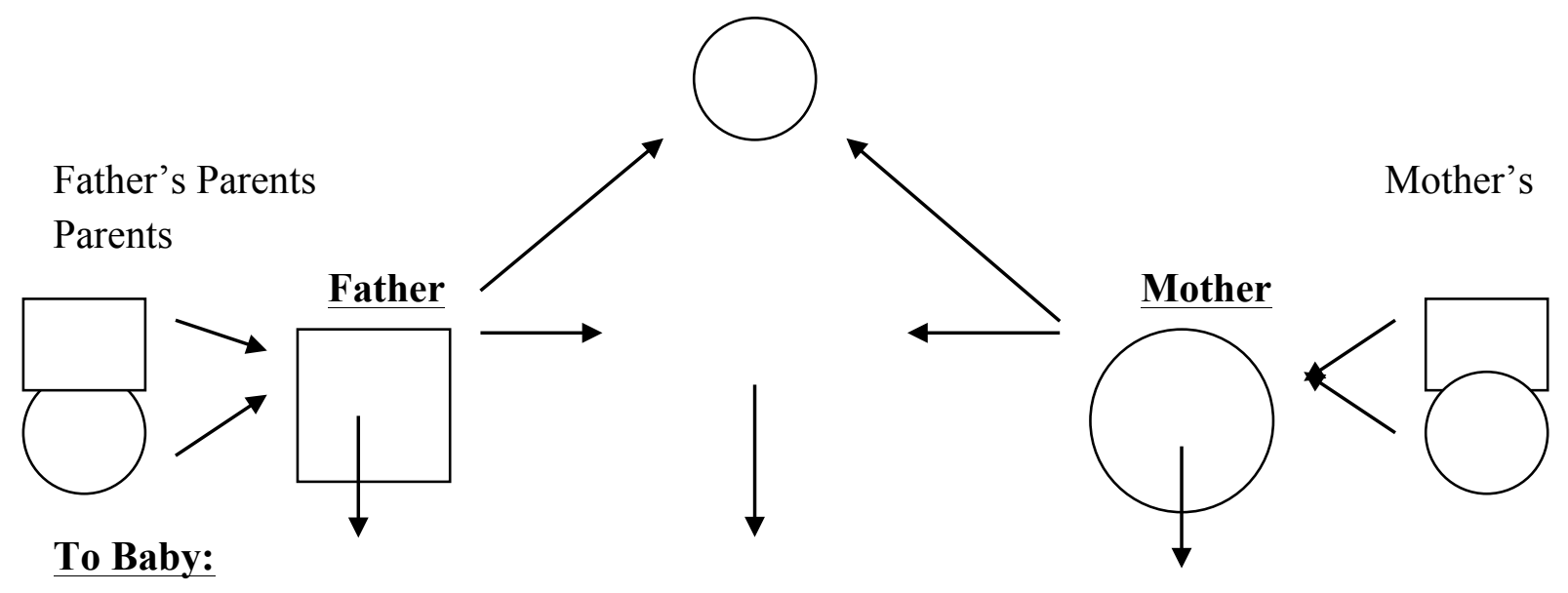

\section{DAYCARE}

Since:

Frequency: (hrs/day; days/week):

Languages spoken:

\section{LANGUAGE BREAKDOWN OF EVERYONE WHO INTERACTS REGULARLY} WITH THE BABY (e.g., parents, grandparents, siblings, babysitter, playmates, friends of parents..)

Are there other people living in your home? $\quad$ YES / NO Include them below

\begin{tabular}{|l|l|l|l|}
\hline Who & Day of Week & Lang Spoken \& \% Breakdown & \# Hrs/day \\
\hline Mom & M-F & & \\
\hline & S-S & & \\
\hline Dad & M-F & & \\
\hline & S-S & & \\
\hline & & & \\
\hline
\end{tabular}




\begin{tabular}{|l|l|l|l|}
\hline & & & \\
\hline & & & \\
\hline & & & \\
\hline & & & \\
\hline
\end{tabular}

Are these percentages different on vacations?

YES NO

If yes, have these vacations occurred since your child was born?

Give frequency, duration, and language breakdown percentages:

\section{LANGUAGE ENVIRONMENT}

In what language do you watch/listen to tv/radio? (give frequency)

TV/Movies : $\quad$ Radio :

If someone walks into your house on a typical day, what languages would they most likely hear the family speaking?

If you had to guess, what language would you say your baby's first words will be in?

\section{PARENTS OVERALL ESTIMATE OF LANGUAGE ENVIRONMENT}

\begin{tabular}{|l|l|}
\hline Language & $\%$ \\
\hline English & \\
\hline French & \\
\hline & \\
\hline
\end{tabular}

\section{FINAL DETAILS}

Has your child ever been treated for ear infections? If yes, how many times?

Does your child have any colds or ear infections today?

Which CLSC is closest to your house?

May we contact you again if we have another study?

Do you know any other parents that would be interested in having their child participate in our study? 